\title{
Lo propio como lugar de exilio. Sobre la poesía de Tato Laviera
}

Susana Rosano / Universidad Nacional de Rosario / susana.rosano@gmail.com

\section{Resumen}

Este trabajo problematiza la poesía de Tato Laviera desde la perspectiva de una doble desterritorialización: con relación a la diáspora puertorriqueña y a la construcción de una lengua híbrida, lo que permite dinamitar el imaginario puertorriqueño amarrado al hispanismo y a una idea de pureza cultural y lingüística. Desde la perspectiva de los estudios culturales y con un abordaje teórico que discute los alcances de la transculturación, se analiza una serie de tres poemas emblemáticos del autor para trabajar en detalle la construcción de esta poética impura. Se piensa a Tato Laviera aquí como un claro representante de los nuevos modos de escritura que los flujos migratorios impulsores de fenómenos de desterritorialización y desdibujamiento de las fronteras en el mapa latinoamericano ponen en funcionamiento en el despliegue de la globalización.
Palabras clave: poéticas impuras • diáspora • imaginario - transculturación • extraterritorialización

\section{Abstract}

This paper focuses on Tato Laviera's poetry from the perspective of a double desterritorialization: in relation to Puerto Rican's diaspora and the construction of a hybrid language. This issue allows him to destroy the Puerto Rican imaginary tied to Hispanic and a sense of cultural and linguistic purity. From the perspective of cultural studies and with a theoretical approach that discusses the scope of transculturation, this paper discusses a series of three poems of the author to work in detail the construction of this poetic impure.

Key words: hybrid poetics $\bullet$ diaspora $\cdot$ imaginary $•$ transculturation $\cdot$ extraterritorialization

En su ya clásico ensayo «Extraterritorial», George Steiner plantea que una característica de la modernidad la constituye la matriz multilingüe de muchos de sus escritores. Tal es el caso de Samuel Beckett, Oscar Wilde, Jorge Luis Borges, Ezra Pound y, fundamentalmente, de Vladimir Nabokov. Este último escritor escribió toda su obra en la alternancia de tres lenguas, el ruso, el inglés y el francés, lo que para Steiner se configura como el núcleo duro de su arte. 
Será desde aquí que el crítico postule su idea de que esta raza de poetas sin casase convierte en una especie de vagabundos que atraviesan varias lenguas y que empiezan a desconfiar de los poderes del lenguaje, una verdadera revolución lingüística que comienza en la última década del siglo XIX y se enfrenta sin ambages a la pérdida de la casa de la lengua, a la carencia de hogar en tanto pérdida de un centro. Se trata acá de un nuevo tipo de imaginación, la imaginación multilingüe, en un momento histórico que Steiner denomina como la época del refugiado.

En la literatura latinoamericana, esta necesidad lingüística de salirse del español para constituir una lengua poética propia puede rastrearse más allá del expresionismo de César Vallejo y de sus intentos por encontrar un lenguaje que dé cuenta de una nueva sensibilidad. Como plantea Enrique Foffani, Vallejo comparte con Vicente Huidobro, con Oliverio Girondo, con Borges, con César Moro esta experiencia de extraterritorialidad lingüística. Si seguimos la argumentación de Borges en «Kafka y sus precursores», se puede pensar que esta operación ya había sido realizada por los padres del modernismo latinoamericano como Rubén Darío y José Martí. De esta manera, para Darío, el encabalgamiento entre el español y el francés permitió lograr momentos de extrema poeticidad.

Pero esta categoría de extraterritorial nos sirve también para pensar los alcances que tiene la poesía nyuyorriqueña en el desmantelamiento del imaginario puertorriqueño ligado a la idea de lo hispánico, de la pureza lingüística, es decir: fuertemente amarrado a la lengua espańola, al concepto de familia y con una gran resistencia a la norteamericanización. Y también nos sirve para pensar los otros fenómenos que se están dando al interior de los Estados Unidos, donde la población latina ya alcanza la primera minoría con un IO\% y da lugar a producciones literarias como la de los chicanos o la de la literatura cubana escrita en inglés. Junot Díaz — un escritor dominicano que vive adentro del territorio de los Estados Unidos y ganó hace un par de años el premio Pulitzer- puede servirnos de ejemplo de esto último.

Pero me interesa en este ensayo reflexionar sobre el caso de Tato Laviera, un poeta nacido en Santurce en I95I, muerto en 2013 y cabal exponente de la diáspora puertorriqueña, que comenzó a incrementarse fuertemente después de la Segunda Guerra Mundial y que encuentra hoy a Puerto Rico con la mitad de su población viviendo puertas adentro de los Estados Unidos, fundamentalmente en Nueva York. En este sentido, me parece interesante pensarlo no sólo como un claro ejemplo de una doble extraterritorialidad tanto espacial como lingüística (Foffani:83) sino también como un exponente de las poéticas impuras que los flujos migratorios impulsores de fenómenos de desterritorialización y desdibujamiento de las fronteras en el mapa latinoamericano ponen en funcionamiento en el despliegue de la globalización contemporánea. ${ }^{1}$

La poesía niuyorriqueña que comienza a desarrollarse a fines de los años sesenta en inglés representa a los hijos de los inmigrantes proletarios de la década de los cincuenta cuya cultura ya no se identifica con los parámetros de raíces hispánicas sino con una matriz más acentuadamente afrocaribeña. En este 
sentido es interesante lo que plantea Efraín Barradas con relación al hecho de que el puertorriqueńo que se autodenomina neorrican se declara distinto, nuevo; ni puertorriqueńo por entero ni claramente estadounidense.

En esta realidad inmigratoria, se podría en consecuencia hablar de tres generaciones: los que nacieron y se formaron en Puerto Rico; los que nacieron en Puerto Rico y fueron trasladados a USA en su infancia (el caso de Tato Laviera) y los puertorriqueńos de segunda generación, es decir los nacidos y criados en Estados Unidos. Para poder reflexionar más a fondo sobre los alcances de esta poética híbrida que construye Laviera y del tono que abraza su poesía en relación con la de Pedro Pietri — considerado el escritor emblemático de la diáspora puertorriqueña—, voy a construir una serie de tres poemas que seleccioné con el objetivo de leer cómo se construye aquí un nuevo concepto de identidad puertorriqueña, a partir del intenso proceso de transculturación lingüística que significa la construcción del spanglish.

\section{I}

«My Graduation Speech» forma parte del primer libro de poemas de Tato Laviera, La Carreta Made a U-Turn (1979), cuyo nombre parodia y de alguna manera interpela el drama «La carreta», escrito en 1953 por René Marqués, y discute su interpretación. Para Marqués, la experiencia migratoria del puertorriqueño ha sido trágica y en este sentido, su obra aboga por el retorno del emigrante a la isla, con la idea de que se puedan restaurar lo que para él constituyen «valores perdidos».

El título de este poema ya nos remite a una característica de la poesía de Laviera: la ironía. El graduation speech es un verdadero género discursivo en los Estados Unidos, profesado por los estudiantes que se gradúan en la universidad. Acá el poeta va a utilizarlo para reconocer, simplemente, que «está jodío» porque sólo puede hablar español e inglés, pero «no sé leer ninguno bien», y al final el reconocimiento de que tampoco "yo no sé hablar». Desde aquí que podamos pensar a este poema como una reflexión sobre su poética en relación con la tradición de la poesía niuyorriqueña.

Los dos primeros versos, «i think in spanish»; «i write in english», permiten pensar la verdadera raíz bicultural del sujeto que emigra, que debe enfrentarse a la tensión del espacio de la cultura natal que deja atrás y a la nueva topografía que exige una pronta adaptación por parte del emigrado. Se puede notar acá que no sólo no se respeta el uso de las mayúsculas en el inglés sino que, de alguna manera, estas palabras parecen citar y refutar los famosos dichos de Rubén Darío en su artículo "Los colores del estandarte», publicado en I896 en el diario $\mathrm{La}$ Nación como respuesta a Paul Groussac. Es allí donde Darío reconoce que piensa en francés y escribe en español.

En este poema de Tato Laviera el sujeto poético invierte las jerarquías, y reconoce que sólo puede pensar a partir de la lengua considerada sociolingüísticamente inferior, el español. En este sentido, es pertinente el análisis de Alejo López, cuando sostiene que la decisión de Laviera de comenzar su poema en inglés corrobora la necesidad de adaptación del desplazado en la nueva tierra y pone un cierto 
orden interno en la tensión que existe consciente o involuntariamente al interior de cualquier exiliado, entre la cultura natal, íntima, familiar, y la necesidad de adaptarse al nuevo territorio. Para ello necesitará incorporar la nueva lengua de su espacio público, sometiéndose al idioma oficial de ese nuevo territorio, más allá del alto costo de aculturación que esto produce en relación con la lengua materna. De esta manera, la lengua que emerge a continuación en el poema de Laviera da cuenta de la pertenencia íntima que existe entre esa lengua poética y ese sujeto en tránsito, tensionado y atravesado por extremos que lo sujetan irremediablemente a un perpetuo entremedio, desde donde logra que emerja su propia voz.

Desde cierto punto, se puede decir que el poema tematiza la imposibilidad del retorno al país natal: «I want to go back to Puerto Rico/ but I wonder if my kink could live/ in Ponce, Mayagüez and Carolina». Doble sentido aquí de la palabra $k i n k$, en tanto remite a los rulos, las ondas en el pelo que denotan el ascendente afro y a partir de los cuales son estigmatizados muchos puertorriqueńos en los Estados Unidos, ${ }^{2}$ pero también en su acepción en inglés de «trauma, manía, perversión sexual». Doble pertenencia, la identidad rompe con la categoría de territorio: ni acá, ni allá, el sujeto poético se encuentra claramente instalado en la exacta confluencia de dos mundos, en el sentido que le da Homi Bhabha a las identidades del entremedio (in between). ${ }^{3} \mathrm{O}$, en palabras de Luis Rafael Sánchez, «en el espacio de una nación flotante entre dos puertos de contrabandear esperanzas» (22).

El tercer verso de este poema parece remitir al tema de la transculturación que con tanta sutileza propuso Fernando Ortiz para pensar la cultura afrocubana:

Tengo las venas aculturadas

Escribo en spanglish

Abraham in español

Abraham in english

Tato in spanish

"taro» in english ${ }^{4}$

Tonto in both languages (Laviera 1979:17)

Se trataría entonces de un primer momento negativo, el de aculturación lingüística, es decir de un momento de pérdida tanto del español como del inglés, y donde el uso del spanglish se lee como algo peyorativo: «tonto in both languages». Es interesante corroborar aquí que la sintaxis del poema tiene la simplicidad del inglés, más allá del hecho de que sus palabras mezclan ambas lenguas.

En la estrofa siguiente se retoma la tensión de los primeros versos ( $I$ I think in spanish, I write in english»), pero esta vez en relación con la escucha:

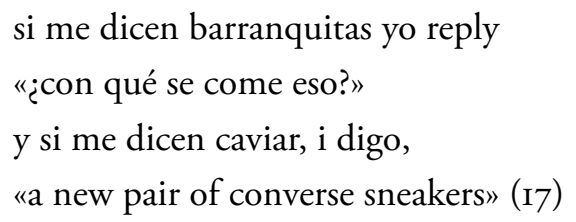


¿Yo pienso lo que escucho? Los versos concluyen en un momento negativo: «ahí supe que estoy jodío, ahí supe que estamos jodíos». Sin embargo, las dos últimas estrofas llevan la tensión del poema hacia una salida en positivo; la aculturación se convierte en una especie de distorsión bilingüe: "Hablo lo inglés matao/ Hablo lo español matao/ No sé leer ninguno bien/ so it is, spanglish to matao/ what i digo".

Se podría pensar que esta estrofa escenifica la división sausseriana entre lengua y habla, en relación con la lengua como el objeto que permite la homogeneidad y la investigación científica, y el habla como el lugar de lo heterogéneo. Y de esta manera, el sujeto poético se resuelve por el habla: «hablo el inglés matao». Es decir: Tato Laviera construye aquí una verdadera poética a partir de esta cuestión de pensar el habla: la lengua desde la cual escribe el sujeto poético es la lengua hablada. Este fuerte matiz de la oralidad ya podía ser leído a partir de la inscripción de los coloquialismos «matao», «jodío», ${ }^{5}$ que movilizan toda la carga afectiva del espańol.

Y desde aquí nos podemos preguntar cómo construye este poema la idea de ciudadanía, y la respuesta es certera: desde la irreverencia, pero también desde la inestabilidad donde parece no haber ni aquí ni allá, ni lugar para el pensamiento binario: english or spanish; spanish or english se resuelve en "spanenglish». Es decir, una construcción poética que transita libremente entre ambas lenguas y procede a conjugar las tonalidades, acentos y ritmos de múltiples registros, de un español afro-caribeño, un inglés urbano y afro-americano. No hay palabras extranjeras para el poeta. Este spanglish es el resultado de resistir a una fuerza de aculturación hegemónica, y da cuentas de que la aculturación puede también ser una forma de resistencia. Las construcciones de Laviera en esta mezcla, en este entrar y salir de una lengua a la otra modifica la naturaleza y la identidad de ambas. No existe acá intercambio de lenguas puras sino una retórica de la impureza, una lengua construida desde los intersticios que hace de la hibridez una celebración y un gozo. ${ }^{6}$

\section{II}

Esta construcción inestable de la identidad parece resolverse en el segundo poema de la serie, «Bochinche bilingüe», que puede ser leído como una verdadera poética de la errancia. Allí el contacto del español y el inglés parecen haber formado un «vernáculo lingüístico» que se basa en la práctica, y por consiguiente en la mezcla de distintas lenguas (la de la calle, la chicana, la afroantillana). Lengua inestable, «el poeta en la cuerda floja», como lo define Enrique Foffani en su artículo de la revista Katatay. El «bochinche» es desorden, fiesta, carnaval. El «bochinche» desmantela las jerarquía, lo alto y lo bajo, lo culto y lo popular; el bochinche derriba fronteras. Porque, al decir del sujeto poético:

\footnotetext{
Los únicos que tienen problemas con el vernáculo lingüístico de nuestra gente cuando habla de
} 


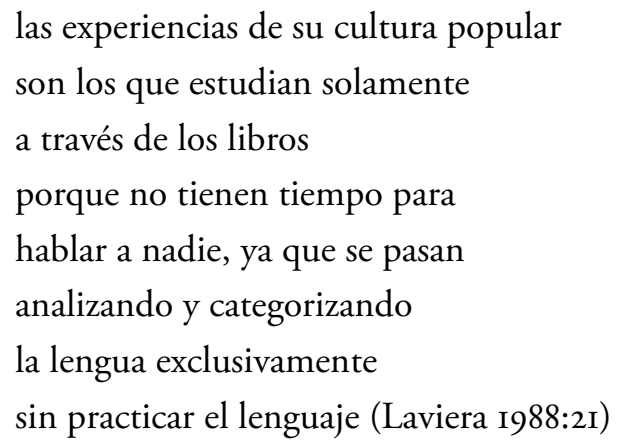

Esta idea de "mezcla de lenguas», esta Babel cosmopolita en que se convierte la calle neoyorquina constituyen a este nuevo sujeto poético que hace estallar la melancolía de los poemas de Pedro Pietri, inmovilizados en el desarraigo que produce la diáspora. Mucho más acá de los Juan, Miguel, Milagros, Olga, Manuel, aquellos personajes del Puerto Rican Obituary (1973), "all died dreaming about america/ waking them up in the middle of the night/ screaming: Mira, Mira, your name is on the winning lottery ticket/ for one hundred thousand dollares» (I6); mucho más acá de aquellos seres afantasmados que arrastraban la impotencia de una vuelta al país natal y la frustración de no alcanzar el American Dream, los poemas de Tato Laviera son una celebración de la hibridez, de esta nueva identidad que se produce a partir del ir y venir que conllevan las raíces portátiles, y dan lugar al nacimiento de un nuevo sujeto, el AmeRican:

\author{
Across forth and across back \\ Back across and forth back \\ Forth across and back and forth \\ Our trips are walking bridges \\ (Cruzar yendo y viniendo \\ Cruzar yendo y viniendo \\ Cruzar de nuevo yendo y viniendo \\ Nuestros viajes son puentes peatonales) (1985:54)
}

\title{
III
}

Pero si los dos primeros poemas de esta serie tematizan la transculturación lingüística, "contienen» un parlamento que habla a favor de la heterogeneidad, el último, «Vaya carnal», escenifica performativamente esa cuestión sonora de estar parado en una esquina de un barrio cosmopolita de Nueva York. Aquí las distintas voces se dejan oír con toda su sonoridad, al ritmo de un rap y, en sintonía con el poema «barrio (forenglishonly)», donde el inglés «se deforma con el calor de tu cultura»; y aquí también «el inglés puro» parece ser «el inglés negro»:

¿sabes? simón, el sonido del este

el vaya, clave, por la maceta, 
que forma parte de un fuerte

lingüismo, raza, pana, borinquen,

azteca, macho, hombre, pulmones

de taínos, de indios, somos,

chicano.riqueños, qué curada,

simón, qué quemada, mi pana,

la esperanza de un futuro,

totalmente nuestro,

tú sabes, tú hueles,

el sabor, el fervor del

vaya, carnal (198I:35)

Como el poema de Tito Madera Smith, que comienza con una bufonada: «he claims he can translate palés matos' black poetry faster than I can talk, and that if I get to smart, he will double translate pig latin english right out of webster's dictionary, do you know him? (él alega que puede traducir la poesía negra de Palés Matós más rápido de lo que yo puedo hablar y, si me creo muy listo, él puede más que traducir directo del diccionario de Webster's la jeringoza del inglés» -Laviera I98I:28-).

De esta manera, la mezcla de lenguas, la fusión del inglés con el español, deviene en esta nueva identidad de "raíces portátiles» de las que habla Julio Ramos y que se construye en la guagua aérea, en esos constantes viajes desde San Juan de Puerto Rico a Nueva York. Una identidad que ya no va a estar más amarrada a la idea de territorio como en las narrativas nacionalistas y donde la cartografía que delimita un adentro y un afuera de lo nacional se ha dinamitado. Tampoco estará más amarrada a la idea de una lengua única, una lengua madre como podría ser el español.

Los poemas de Tato Laviera desbaratan el tono melancólico de añoranza de la patria que circunscribían los discursos románticos sobre el exilio y, en este sentido, el espacio polifónico es una ganancia (se puede entrar y salir de la lengua): estos poetas bilingües tienen dos casas, pero también, como dice Enrique Foffani, dos intemperies.

En la época del refugiado de la cual habla George Steiner, la patria ahora se construye con la materialidad de la lengua y sólo puede ser cantada en los night clubs, en las barberías, como lo anuncia magistralmente el poema "Migración». Es decir: la única posibilidad que tendrán los poetas es la de construirse una patria con el lenguaje. Y en el cuarto piso que hoy en día los puertorriqueños alquilan a los Estados Unidos (según afirma José Luis González) se desbaratan para siempre los imaginarios nacionales unidos al hispanismo. Desde aquí, la lengua será para Tato Laviera un ejercicio, una práctica cotidiana que se hace en la calle, una lengua híbrida que desmantela las viejas categorías de lo culto y lo popular, de la oralidad y la escritura, en donde el bochinche bilingüe se plantea como una fiesta pero también como la ruptura de los discursos conservadores y de sus ideas de pureza, y permite mostrar los condimentos africanos de Puerto Rico, largamente silenciados por la tradición hispanófila del nacionalismo. 


\section{Notas}

1 Para esta cuestión, remito al excelente ensayo de Julio Ramos, «Migratorias», donde se analiza la problemática del exiliado, descentrado entre dos mundos. A partir de la idea de Theodor Adorno de que «en el exilio la única casa es la escritura», Ramos confronta dos poemas emblemáticos: «Domingo triste», de José Martí, de fines del siglo XIX, y «Migración», de Tato Laviera, de 1988. Ramos lee aquí los deslizamientos de sentido que se producen en la manera de concebir la identidad en el exilio. El crítico afirma allí que entre Martí y Laviera, se astillan «las redes topográficas y las categorías duras de la territorialidad y su metaforización telúrica».

2 En relación con la mirada racista que sufren los puertorriqueños en Nueva York, Luis Rafael Sánchez sostiene que, una vez arribado a los Estados Unidos, «se patentiza la capacidad de sobrevivencia y la fibra de ese puertorriqueño que muele vidrio con el pecho al instalarse en la extraña nación a que alude Noel Estrada en su oda musical —el idioma diferente, la hostilidad contra el emigrante sin recursos, los inviernos infernales, el racismo enfermizo que pone en su sitio a cualquier persona del pelo malo o kinky y la tez de oscura a prieta» (7).
${ }^{3}$ En una entrevista que le realiza Paul Thompson que está recogida en el libro Migration and Identity, Homi Bhabha sostiene que estas identidades del entremedio (in between) están situadas en un espacio intersticial subversivo, ya que niegan y se escabullen por medio de la ambivalencia y la ambigüedad la asimilación de las categorías de identidad y a los conceptos de pureza, origen o tradición.

${ }^{4} \mathrm{La}$ «I» en lugar de la «t» de Tato convierte la pronunciación de este nombre en inglés en "Taro», ya que la pronunciación de la «t» es mucho más suave en inglés que en español.

5 Alejo López advierte que el adjetivo «matao» inscribe el acento caribeńo por medio de la sufijación «ao», y al mismo tiempo designa esta fractura de la pureza y estandarización lingüística, lo que se denomina en inglés «borken english».

6 Esta conexión entre lengua e identidad está muy clara, por ejemplo, en el poema "Brava», donde el sujeto poético relaciona el ataque a su lengua con un ataque a su identidad étnica: «tú sabes que yo soy that/ I am a puertorriqueña in/ English and thre's nothing/ you can do but to accept/ it como yo soy sabrosa...» (AmeRican 63).

\section{Bibliografía}

Barradas, Efraín (1998). Partes de un todo. Ensayos y notas sobre literatura puertorriqueña en los Estados Unidos. San Juan de Puerto Rico: Universidad de Puerto Rico.

Borges, Jorge Luis (I95I). "Kafka y sus precursores», en Obras completas 1952-1972. Buenos Aires: Emecé, 1960, 88-90.

DARÍo, RubÉN (I896). «Los colores del estandarte», en Ricardo Gullón, editor. El modernismo visto por los modernistas. Barcelona: Guadarrama, 1980, 49-57.

FofFANi, ENRique (2005). «Tato Laviera. El poeta sobre la cuerda floja». Katatay I/2, 82-86.

GonzÁlez, José Luis (I980). El país de los cuatro pisos. Ríos Piedras: Huracán.

Laviera, Tato (i979). La carreta made a U-turn. Houston: Arte Público Press, I984. (198I). Enclave. Houston: Arte Público Press. (1985). AmeRican. Houston: Arte Público Press. (1988). Mainstream Ethics. Ética corriente. Houston: Arte Público Press.

López, Alejo (20IO). "La retórica Spanglish de Tato Laviera» [en línea]. Consultado el i6 de mayo de 2014 en http://blogs.ffyh.unc.edu.ar/centenariojoselezamalima/files/20Io/o2/alejo-lopez.pdf Pietri, Pedro (1973). Puerto Rican Obituary. Obituario puertorriqueño. San Juan de Puerto Rico: Isla Negra Editores, 2006. Traducción por Alfredo Matilla Rivas. 
Ramos, Julio (1996). «Migratorias». Paradojas de la letra. Caracas: eXcultura, Universidad Andina Simón Bolívar, 177-186.

SÁnchez, Luis Rafael (1994). "La guagua aérea». La guagua aérea. San Juan de Puerto Rico: Cultural, 2002,II-22.

STEINER, GEORGE (197I). «Extraterritorial». Extraterritorial. Ensayos sobre literatura y la revolución del lenguaje. Buenos Aires: Adriana Hidalgo, 2000, 15-26. Traducción de Edgardo Russo.

Thompson, Paul (1994). «Homi Bhabha interviewed by Paul Thompson», en Rina Benmayor y Andor Skotnes, editores. Migration and Identity. Oxford, New York: Oxford University Press, I83-186. 